\title{
TPK gene products mediate CAMP-independent thermotolerance in Saccharomyces cerevisiae
}

\author{
P. J. Coote, ${ }^{*}$ M. V. Jones, K. Edgar and M. B. Cole \\ Unilever Research, Colworth Laboratory, Sharnbrook, Bedford MK44 ILQ, UK
}

(Received 7 April 1992; revised 27 July 1992; accepted 18 August 1992)

\begin{abstract}
Incubation of Saccharomyces cerevisiae with the plant cytokinin $N^{6}-\left(\Delta^{2}\right.$-isopentenyl)adenine (2iP) resulted in an induction of thermotolerance similar to that induced by sublethal temperatures. Intracellular cAMP levels did not change significantly either during incubation at a sublethal temperature or in the presence of $2 \mathrm{iP}$ or ethanol. This suggested that stress-induced thermotolerance is triggered by a mechanism independent of cAMP activation. However, measurement of stress-induced thermotolerance in two mutant strains $(t p k 1, t p k 2, T P K 3 ; t p k 1, T P K 2$, $t p k 3$ ) each deficient in two of the catalytic subunits of the cAMP-dependent protein kinase (cAPK), revealed that sublethal heat induces thermotolerance by a mechanism part-mediated by the catalytic subunits of cAPK. In contrast, 2iP and ethanol induced thermotolerance by a mechanism fully dependent on the catalytic subunits of cAPK for expression. Therefore, this implies there must be an alternative novel mechanism, other than cAMP, for activating cAPK during stress. Sublethal heating resulted in large increases in intracellular trehalose levels which correlated with the induction of thermotolerance. However, incubation in $2 \mathrm{iP}$ or ethanol had no significant effect. This suggests trehalose synthesis is either coincidental with heat stress or that different stress factors induce thermotolerance by alternative mechanisms. Incubation with protein synthesis inhibitors reduced the levels of trehalose synthesized during sublethal heating, suggesting that synthesis of trehalose-6-phosphate synthase during heat stress could be accounting for the increased trehalose levels.
\end{abstract}

\section{Introduction}

Among the physiological factors implicated in the acquisition of increased thermotolerance in stressed cells are heat-shock proteins (HSPs) (Sanchez \& Lindquist, 1990); trehalose (Wiemken, 1990); membrane-bound ATPase (Coote et al., 1991 a; Panaretou \& Piper, 1990), and the $\mathrm{G}_{0}$ stage of the cell cycle (Plesset et al., 1987). In addition, a decrease in intracellular $\mathrm{pH}\left(\mathrm{pH}_{\mathrm{i}}\right)$ has been implicated as a common physiological trigger inducing some of these mechanisms (Coote et al., 1991a). However, internal acidification is also known to activate the RAS-adenylate cyclase pathway and thus regulate cAMP metabolism (Valle et al., 1986; Thevelein, 1991). It has been suggested that a decline in intracellular cAMP is an induction signal for many heat-shock genes (Piper, 1990; Praekelt \& Meacock, 1990) and for the cessation of cell division in $\mathrm{G}_{1}$ (Matsumoto et al., 1983). Therefore, it is possible that cAMP metabolism, perhaps

* Author for correspondence. Tel. (0234) 222377; fax (0234) 222277.

Abbreviations: cAPK, cyclic-AMP-dependent protein kinase; HSP, heat-shock protein; $2 \mathrm{iP}, N^{6}-\left(\Delta^{2}\right.$-isopentenyl)adenine. regulated by $\mathrm{pH}_{\mathrm{i}}$ fluctuations, is involved in the induction of increased thermotolerance in Saccharomyces cerevisiae.

Intracellular levels of cAMP are sensitive to environmental change and many enzymes are regulated by changes in cAMP levels (Krebs \& Beavo, 1979), e.g. trehalase (Van der Plaat, 1974) and fructose-1,6-bisphosphatase (Mazon et al., 1982). A large transient intracellular peak of cAMP occurs upon addition of glucose to derepressed cells (Thevelein \& Beullens, 1985) and there is some evidence of a slower and smaller increase with heat-shock treatment (Camonis et al., 1986; Thevelein, $1984 a$ ).

cAMP-mediated regulation in eukaryotes is principally via a protein phosphorylation cascade (Thevelein, 1988) which activates a cAMP-dependent protein kinase (cAPK) which, in turn, phosphorylates and either activates, or deactivates, enzymes and thus brings about the cellular response to external stimuli. The cAPK consists of a regulatory subunit BCY1 (Toda et al., $1987 a$; Cannon \& Tatchell, 1987), to which cAMP binds, and three catalytic subunits, encoded by TPK1,TPK2 and TPK3 (Toda et al., 1987 b; Cannon \& Tatchell, 1987), 
whose action mediates the effects of cAMP (Beebe \& Corbin, 1986). These three TPK genes code for proteins with $75 \%$ homology (Toda et al., 1987b) and, although deletion of all three is lethal, normal growth can be achieved with only one of the subunits. Strains with a mutation in the regulatory subunit of the protein kinase (bcyl) have constitutive activation of the cAPK catalytic subunits rendering them independent of cAMP levels (Matsumoto et al., 1982). In addition, they cannot acquire thermotolerance or synthesize HSPs (Shin et al., 1987), and cannot accumulate trehalose (Hottiger et al., 1989). In contrast, strains disrupted in the adenyl cyclase gene (cyrl-2), which catalyses the formation of cAMP from ATP, are always thermotolerant. However, these strains constitutively synthesize HSPs (Shin et al., 1987) and have high levels of trehalose (Hottiger et al., 1989). Clearly, there is substantial evidence of a role for cAMP metabolism in the induction of trehalose synthesis and thermotolerance.

Phosphorylation either activates or deactivates a number of enzymes resulting in the accumulation or breakdown of important intracellular compounds, including trehalose (Krebs \& Beavo, 1979). Trehalose, a non-reducing disaccharide, was initially thought to be mainly a storage carbohydrate (Thevelein, 1984b), but this is now thought to be unlikely due to the unfavourable energetics of conversion to and from a storage polymer (Wiemken, 1990). Trehalose is also thought to act as a 'stress protectant' (Hottiger et al., 1987a; Attfield, 1987). It is believed to preserve membranes and proteins on dehydration, and stabilize enzymes against thermal damage (Crowe et al., 1987). Significantly, intracellular trehalose has been shown to increase enormously on exposure to sublethal heat (Hottiger et al., 1987a; Attfield, 1987).

Both the synthetic and degradative enzymes responsible for trehalose metabolism, trehalose-6-phosphate synthase and neutral trehalase increase their activity during sublethal heat-shock (Hottiger et al., 1987b). It is believed that these enzymes are principally regulated by cAMP-dependent phosphorylation (Thevelein, 1988). When cAMP levels are high, neutral trehalase and trehalose-6-phosphate synthase are believed to be phosphorylated and activated, deactivated respectively (Panek et al., 1987; Wiemken \& Schellenberg, 1982). However, some authors have reported only a small increase in cAMP upon sublethal heat-shock and also an increase in trehalose levels. Therefore, it seems trehalose may be regulated by means other than cAMP-dependent phosphorylation. Indeed, it has been suggested that trehalose-6-phosphate synthase is a HSP (Hottiger et al., $1987 \mathrm{~b}$ ). So, the role of cAMP-mediated regulation and the role of trehalose synthesis during stress has not yet been clearly elucidated.
In this work we have studied the effect of a plant cytokinin, $N^{6}$-( $\Delta^{2}$-isopentenyl)adenine (2iP), believed to interfere with cAMP metabolism (Hecht et al., 1974; Coppola et al., 1976) on the stress response in Saccharomyces cerevisiae. Also, the effects of $2 \mathrm{iP}$, sublethal heat and ethanol on levels of intracellular cAMP, the induction of thermotolerance and trehalose synthesis were investigated in wild-type $S$. cerevisiae and in strains with mutations in genes for two of the catalytic subunits of cAPK.

\section{Methods}

Organisms and growth conditions. Four strains of Saccharomyces cerevisiae were used; CMC 3236; W3031A (ade2-1, his3-11,15, leu23,112, trpl-1, wa3-1, canl-100); MB12, as W3031A plus tpk1::LEU2 tpk2::HIS3; MB13, as W3031A plus tpk1::LEU2 tpk3::URA3. W3031A, MB 12 and MB 13 were kindly provided by Dr P. Piper, UCL, London, UK. Strain CMC 3236 was used as a wild-type control for comparison with the mutant strains.

Cells were grown to late-exponential phase at $30^{\circ} \mathrm{C}$ in YEPD $(3 \%$, $w / v$, glucose, $2 \%$, w/v, yeast extract, $1 \%$, w/v, Bacto-peptone). Strain CMC 3236 was grown in YEPD containing $0.7 \%$ glucose for measurement of cAMP, and Malt Extract Broth (MEB) (Oxoid) for measurements of thermotolerance.

\begin{abstract}
Measurement of thermotolerance. Samples $(10 \mathrm{ml})$ of late-exponential S. cerevisiae CMC 3236 were centrifuged, washed and resuspended in fresh broth, and allowed to resuscitate at $25^{\circ} \mathrm{C}$ for $30 \mathrm{~min}$. The cells were then incubated with either $50 \mu \mathrm{g} 2 \mathrm{iP}$ (Sigma) $\mathrm{ml}^{-1}, 6 \%(\mathrm{v} / \mathrm{v})$ ethanol, $100 \mu \mathrm{g}$ cycloheximide (Sigma) $\mathrm{ml}^{-1}, 50 \mu \mathrm{g} 2 \mathrm{iP} \mathrm{ml} \mathrm{plus}^{-1}$ plo $\mu \mathrm{g}$ cycloheximide $\mathrm{ml}^{-1}$ for $60 \mathrm{~min}$ with shaking at $25^{\circ} \mathrm{C}$, or sublethally heat-stressed at $42^{\circ} \mathrm{C}$ for $30 \mathrm{~min}$ in a shaking waterbath. After incubation, a $50 \mu \mathrm{l}$ sample of culture was inoculated into $950 \mu \mathrm{l}$ of preheated fresh broth at $54{ }^{\circ} \mathrm{C}$ in a modified thermocouple block calibrator DB-40L (Techne, Cambridge) (Coote et al., 1991 b). Samples $(100 \mu \mathrm{l})$ were taken at various times throughout an 11 min heating period and immediately inoculated into $5 \mathrm{ml}$ of fresh broth. Cells were resuscitated for $1 \mathrm{~h}$, serially diluted, and plated in duplicate on Plate Count Agar (PCA) (Oxoid). The plates were incubated for $48 \mathrm{~h}$ at $30^{\circ} \mathrm{C}$ before counting.

Induction of thermotolerance by $2 \mathrm{iP}$, ethanol or incubation at $42^{\circ} \mathrm{C}$ in $S$. cerevisiae strains W3031 A, MB12 and MB13 was determined in cells which were prepared as above. However, following addition of 2iP, ethanol or transfer to $42^{\circ} \mathrm{C}, 50 \mu \mathrm{l}$ samples were taken after 0,15 , 30,45 and $60 \mathrm{~min}$ incubation and viability was determined after heating at $54^{\circ} \mathrm{C}$ for $5 \mathrm{~min}$ as before. Heating times of 5 and $11 \mathrm{~min}$ at $54^{\circ} \mathrm{C}$ were used to give similar losses of viable numbers in the different strains.
\end{abstract}

Measurement of trehalose. Trehalose levels were measured after addition of $2 \mathrm{iP}\left(50 \mu \mathrm{g} \mathrm{m}^{-1}\right)$, ethanol $(6 \%, \mathrm{v} / \mathrm{v})$, incubation at $42^{\circ} \mathrm{C}$ (heat shock), and after a $30 \mathrm{~min}$ pre-incubation in cycloheximide $\left(100 \mu \mathrm{g} \mathrm{ml}^{-1}\right)$. Samples $(20 \mathrm{ml})$ of late-exponential culture were taken 0 , $15,30,45$ and $60 \mathrm{~min}$ after treatment and harvested by filtration (Whatman GF/C), washed three times with $10 \mathrm{ml}$ of ice-cold saline, and extracted with $2 \mathrm{ml}$ of ice-cold $500 \mathrm{~mm}$-trichloroacetic acid. Trehalose in the acid extracts was measured by the anthrone assay as described by Lillie \& Pringle (1980). 
Measurement of intracellular CAMP. cAMP levels were determined in S. cerevisiae CMC 3236 by the method of Thevelein et al. (1987) using Amersham cAMP assay kits.

Reproducibility of results. Unless otherwise stated all experiments were done at least twice and graphs of representative results are shown.

\section{Results}

\section{Effect of 2iP and sublethal heat on trehalose synthesis} and thermotolerance

Cells, previously incubated at $25^{\circ} \mathrm{C}$, showed over a 100 fold loss in initial viable numbers after heating at $54^{\circ} \mathrm{C}$ for $11 \mathrm{~min}$ (Fig. $1 a, b$ ). Cells incubated at $25^{\circ} \mathrm{C}$ contained low, unchanging levels of trehalose (Fig. 2). However, cells having a prior incubation at $42^{\circ} \mathrm{C}$ for 30 min showed less than a 10 -fold reduction in starting numbers after $11 \mathrm{~min}$ at $54^{\circ} \mathrm{C}$ (Fig. $1 \mathrm{a}$ ). Furthermore, incubation at $42{ }^{\circ} \mathrm{C}$ resulted in a 20 -fold increase above initial trehalose levels after $60 \mathrm{~min}$ (Fig. 2). Preincubation in $50 \mu \mathrm{g} 2 \mathrm{iP} \mathrm{ml} l^{-1}$ for $60 \mathrm{~min}$ also resulted in a similar induction of thermotolerance at $54^{\circ} \mathrm{C}$ (less than a 10-fold reduction in starting numbers after $11 \mathrm{~min}$ ) (Fig. 1 a). However, pre-incubation in $2 \mathrm{iP}$ had little effect on trehalose levels which remained low (Fig. 2). Also, incubation in $6 \%$ ethanol, which has also been shown to increase thermotolerance (Coote et al., 1991a), only increased trehalose by a factor of approximately 2 -fold above starting levels after $60 \mathrm{~min}$ incubation, which is significantly less than the increase induced by sublethal heat (Fig. 2). Pre-incubation with $2 \mathrm{iP}$ for $60 \mathrm{~min}$ followed by sublethal heating at $42{ }^{\circ} \mathrm{C}$ induced a similar degree of thermotolerance to $2 \mathrm{iP}$ or sublethal heat alone (Fig. 1a).
Pre-incubation with $100 \mu \mathrm{g}$ cycloheximide $\mathrm{ml}^{-1}$ alone had no effect on heat resistance (Watson et al., 1984), as both control cells and cells pre-incubated with cycloheximide showed an approximate 100 -fold reduction in starting numbers after $11 \mathrm{~min}$ at $54^{\circ} \mathrm{C}$ (Fig. 1 b). As before, cells pre-incubated with $2 \mathrm{iP}\left(50 \mu \mathrm{g} \mathrm{ml}^{-1}\right)$ for $60 \mathrm{~min}$ at $25^{\circ} \mathrm{C}$ showed less than a 10 -fold reduction in starting numbers after $11 \mathrm{~min}$ at $54^{\circ} \mathrm{C}$. However, incubation with cycloheximide and $2 \mathrm{iP}$ completely abolished the induction of thermotolerance by $2 \mathrm{iP}$, and indeed, resulted in an even larger reduction in starting numbers (approximately 9000 -fold after $11 \mathrm{~min}$ at $54^{\circ} \mathrm{C}$ ) than the control.

Incubation at $25^{\circ} \mathrm{C}$ with cycloheximide $\left(100 \mu \mathrm{g} \mathrm{ml}^{-1}\right)$ had no effect on levels of trehalose, which remained low as in the untreated control (Fig. 3). After sublethal heating for $60 \mathrm{~min}$ at $42^{\circ} \mathrm{C}$, trehalose synthesis increased approximately 20 -fold above starting levels. However, this was reduced by approximately $60 \%$ in the presence of cycloheximide with only an approximate 8-fold increase in trehalose after $60 \mathrm{~min}$ at $42^{\circ} \mathrm{C}$ (Fig. 3).

\section{Effect of 2iP, sublethal heat or ethanol on levels of cAMP}

Addition of $100 \mathrm{~mm}$-glucose to derepressed cells resulted in a large transient peak in cAMP levels $45 \mathrm{~s}$ after addition of glucose (Fig. 4) (Thevelein et al., 1987). However, addition of $50 \mu \mathrm{g} 2 \mathrm{iP} \mathrm{ml} \mathrm{m}^{-1}$, ethanol $(6 \%)$ or instantaneous heat-shock at $42^{\circ} \mathrm{C}$ had no significant effect, within experimental error, on levels of cAMP after 5 min incubation (Fig. 4). Incubation with $2 \mathrm{iP}$, ethanol or at $42^{\circ} \mathrm{C}$ for a further $55 \mathrm{~min}$ resulted in no further change in cAMP levels (results not shown). Control cells showed no change in cAMP levels over the
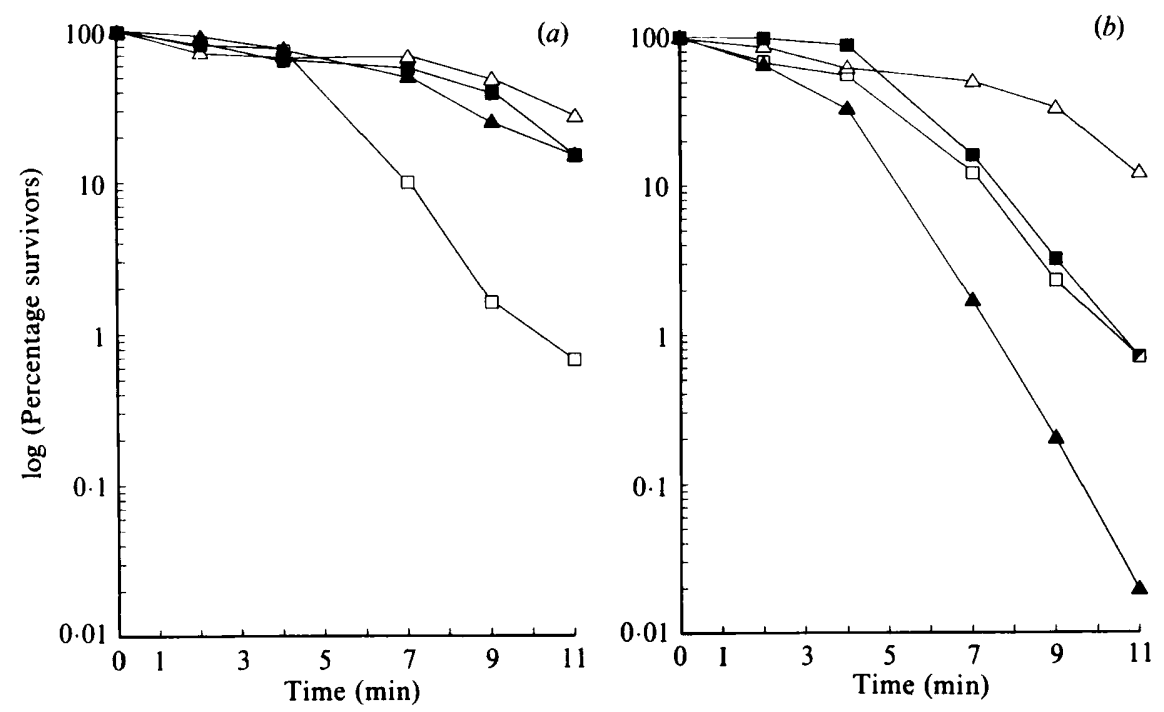

Fig. 1. Thermal inactivation of $S$. cerevisiae 3236. (a) After pre-incubation with $2 \mathrm{iP}$ and sublethal heat stress. Late-exponential phase cells were harvested, resuspended in fresh MEB, and heated at $54{ }^{\circ} \mathrm{C}$ after $60 \mathrm{~min}$ incubation at $25^{\circ} \mathrm{C}(\square)$; $60 \mathrm{~min}$ incubation at $25^{\circ} \mathrm{C}$ with $50 \mu \mathrm{g} 2 \mathrm{iP} \mathrm{ml}$ $(\triangle) ; 30 \mathrm{~min}$ incubation at $42{ }^{\circ} \mathrm{C}(\square)$; and $60 \mathrm{~min}$ incubation with $50 \mu \mathrm{g} 2 \mathrm{iP} \mathrm{ml}{ }^{-1}$ at $25^{\circ} \mathrm{C}$ followed by $30 \mathrm{~min}$ at $42^{\circ} \mathrm{C}(\boldsymbol{A})$. (b) After pre-incubation with $2 \mathrm{iP}$ and cycloheximide. Late-exponential phase cells were harvested, resuspended in fresh MEB and heated at $54^{\circ} \mathrm{C}$ after 60 min incubation at $25^{\circ} \mathrm{C}(\square) ; 60 \mathrm{~min}$ incubation at $25^{\circ} \mathrm{C}$ with $50 \mu \mathrm{g} 2 \mathrm{P} \mathrm{ml}^{-1}(\triangle) ; 60 \mathrm{~min}$ incubation with $100 \mu \mathrm{g}$ cycloheximide $\mathrm{ml}^{-1}(\square)$; and $60 \mathrm{~min}$ incubation with $50 \mu \mathrm{g} 2 \mathrm{iP} \mathrm{ml} \mathrm{m}^{-1}$ and $100 \mu \mathrm{g}$ cycloheximide $\mathrm{ml}^{-1}(\boldsymbol{A})$. 


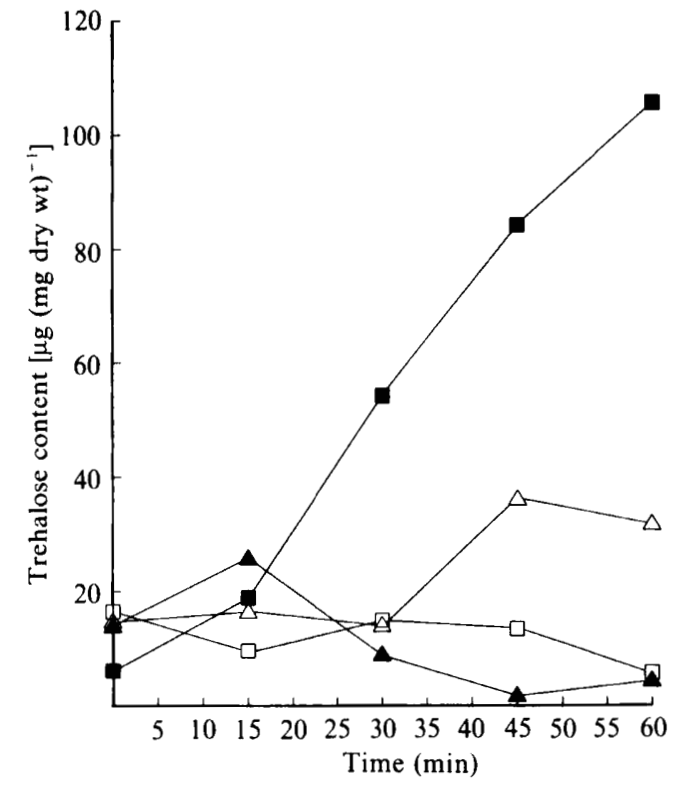

Fig. 2. Effect of different stress treatments on intracellular trehalose levels in $S$. cerevisiae 3236. Trehalose was measured as glucose equivalent from $20 \mathrm{ml}$ samples of late-exponential phase culture after 0 , $15,30,45$ and $60 \mathrm{~min}$ incubation at $30^{\circ} \mathrm{C}(\square) ; 42^{\circ} \mathrm{C}(\mathbf{D}) ; 30^{\circ} \mathrm{C}$ with $6 \%(\mathrm{v} / \mathrm{v})$ ethanol $(\triangle)$; and $30^{\circ} \mathrm{C}$ with $50 \mu \mathrm{g} 2 \mathrm{iP} \mathrm{ml} \mathrm{m}^{-1}(\Delta)$.

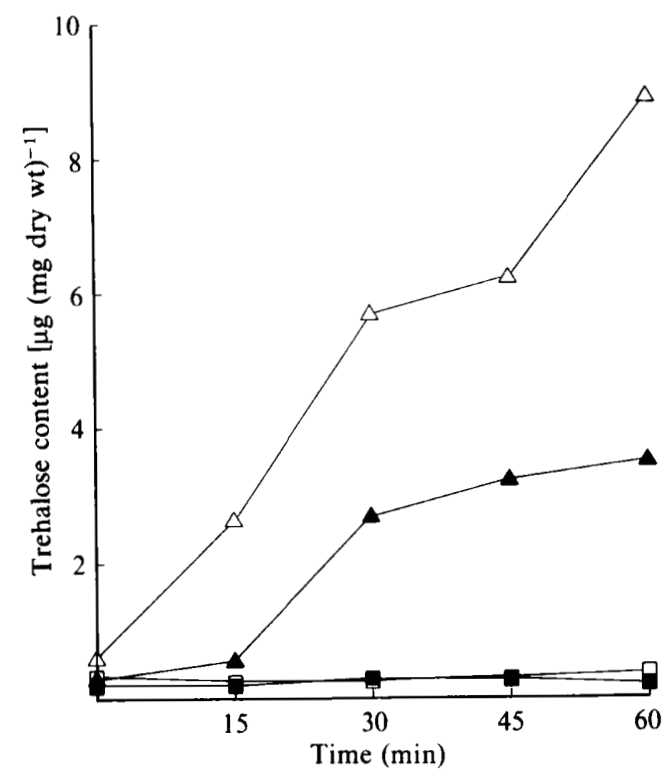

Fig. 3. Effect of cycloheximide on stress-induced synthesis of trehalose measured as glucose equivalent in late-exponential phase cells of $S$. cerevisiae 3236. A culture was divided equally, one half incubated at $30^{\circ} \mathrm{C}$, the other at $30^{\circ} \mathrm{C}$ with $100 \mu \mathrm{g}$ cycloheximide $\mathrm{ml}^{-1}$ for $30 \mathrm{~min}$. Measurements were made from $20 \mathrm{ml}$ samples of culture after $0,15,30$, 45 and $60 \mathrm{~min}$ incubation at $30^{\circ} \mathrm{C}(\square) ; 30^{\circ} \mathrm{C}$ with $100 \mu \mathrm{g}$ cycloheximide $\mathrm{ml}^{-1}(\square) ; 42^{\circ} \mathrm{C}(\triangle)$; and $42^{\circ} \mathrm{C}$ with $100 \mu \mathrm{g}$ cycloheximide $\mathrm{ml}^{-1}$ (A).

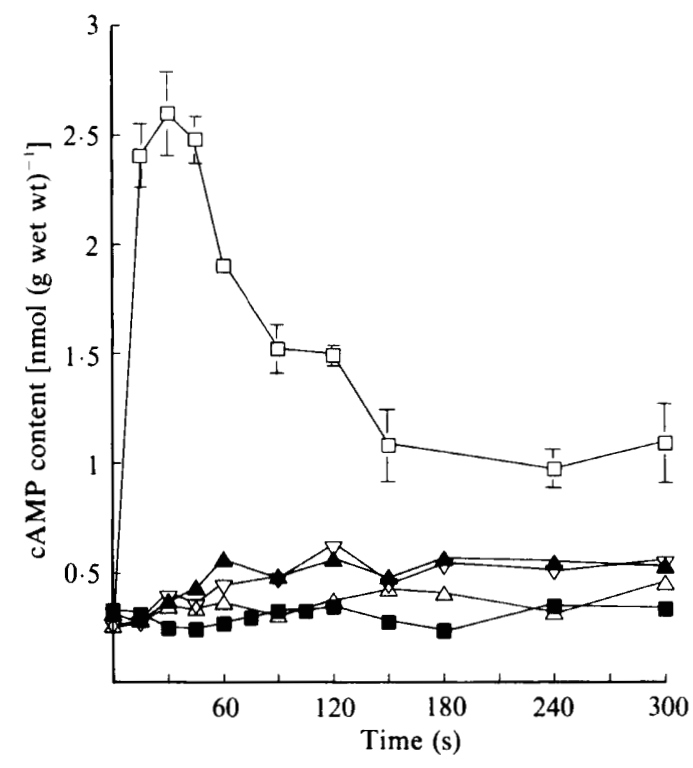

Fig. 4. Cyclic AMP levels measured in late-exponential phase cells of $S$. cerevisiae 3236 resuspended in MES, pH 6.0, after addition of glucose $(100 \mathrm{mM})(\square) ; 2 \mathrm{iP}\left(50 \mu \mathrm{g} \mathrm{ml}^{-1}\right)(\triangle)$; ethanol $(6 \%, \mathrm{v} / \mathrm{v})(\Delta)$; incubation at $42^{\circ} \mathrm{C}(\nabla)$; and a control with no additions $(\square)$. The mean values of two experiments are shown. Error bars are shown on the glucose plot indicating the standard deviations. Error bars are omitted from the 2iP, ethanol and $42{ }^{\circ} \mathrm{C}$ plots for the sake of clarity but were within the range of 0.018 to $0.334 \mathrm{nmol}$ cAMP ( $\mathrm{g}$ wet $\mathrm{wt})^{-1}$.

same period of time. In addition, incubation of cells in the presence of $2 \mathrm{iP}$ for $60 \mathrm{~min}$ had no effect on the ability of glucose to induce a large, transient peak in cAMP (results not shown). Therefore, 2iP has no major effect on either the steady-state cellular level of cAMP or the glucose-induced rapid synthesis of cAMP.

\section{Thermotolerance and trehalose synthesis in strains deficient in two catalytic subunits of the cAPK}

Induction of thermotolerance and trehalose synthesis was measured in three strains sharing auxotrophic markers. However, two of the strains also had disruptions in two of the three TPK genes. Strain W3031A showed an approximate 20 -fold increase above starting levels of trehalose after incubation for $60 \mathrm{~min}$ at $42{ }^{\circ} \mathrm{C}$. There was also a 12 -fold increase in thermotolerance at $54^{\circ} \mathrm{C}$ for $5 \mathrm{~min}$ after the same incubation period (Fig $5 a$ ). However, strain MB12 (deficient in TPKI and $T P K 2$ ), after $60 \mathrm{~min}$ incubation at $42^{\circ} \mathrm{C}$, showed increased trehalose synthesis of only 11 -fold above starting levels, and increased thermotolerance of approximately 4-fold (Fig. $5 b$ ). In strain MB13 (deficient in $T P K 1$ and $T P K 3$ ), the increases were even less, only 8fold for trehalose and 3-fold for thermotolerance (Fig. $5 c)$. Incubation of W3031 A with $2 \mathrm{iP}\left(50 \mu \mathrm{g} \mathrm{ml}^{-1}\right)$ and 


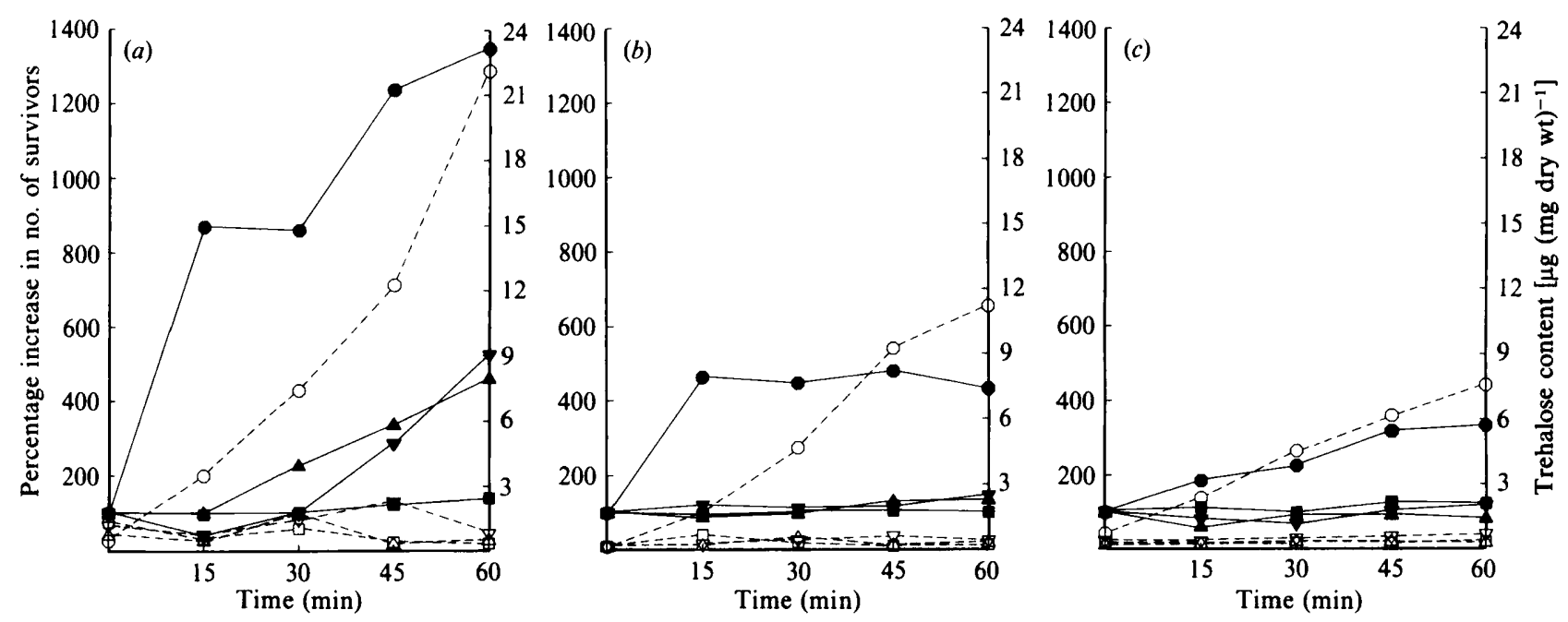

Fig. 5. Induction of thermotolerance and trehalose synthesis in $S$. cerevisiae strains by $2 \mathrm{iP}$, ethanol and $42^{\circ} \mathrm{C}$. Thermotolerance was measured at $54^{\circ} \mathrm{C}$ for $5 \mathrm{~min}$ after $0,15,30,45$ and $60 \mathrm{~min}$ exposure to $\left.25^{\circ} \mathrm{C}(\square), 2 \mathrm{iP}(50 \mu \mathrm{g} \mathrm{ml})^{-1}\right)(\boldsymbol{N})$, ethanol $\left(6 \%\right.$, v/v) $(\nabla)$ and $42{ }^{\circ} \mathrm{C}$ (O). Increased thermotolerance was expressed as the percentage increase in survivors after heating at $54^{\circ} \mathrm{C}$ for 5 min when the number of survivors after zero time for each treatment was expressed as $100 \%$. Trehalose was also measured after $0,15,30,45$ and $60 \mathrm{~min}$ exposure to $25^{\circ} \mathrm{C}(\square), 2 \mathrm{iP}\left(50 \mu \mathrm{g} \mathrm{ml}^{-1}\right)(\triangle)$, ethanol $(6 \%, \mathrm{v} / \mathrm{v})(\nabla)$, and $42^{\circ} \mathrm{C}(\mathrm{O})$. Thermotolerance and trehalose synthesis were measured in this way in three strains : (a) W3031A (TPK1 TPK2 TPK3); (b) MB12 (tpk1 tpk2 TPK3); (c) MB13 (tpk1 TPK2 tpk3).

ethanol $(6 \%)$ resulted in an approximate 5 -fold increase in thermotolerance after $60 \mathrm{~min}$, but no increase in trehalose levels (Fig. 5a). Significantly, the induction of thermotolerance in strains MB12 and MB13 by incubation in $2 \mathrm{iP}$ or ethanol was completely abolished (Fig. $5 b$, c). Both MB12 and MB13 had similar responses to the applied stress factors in terms of the levels of trehalose synthesized and thermotolerance induced. In all strains, the untreated/uninduced controls showed unchanging levels of thermotolerance and trehalose when incubated over the same period.

\section{Discussion}

It has been proposed that perturbation in $\mathrm{pH}_{\mathrm{i}}$ may act as a rapid physiological signal triggering the stress response in $S$. cerevisiae, which results in increased thermotolerance (Coote et al., 1991a). In this work, we have extended these studies to include the role of cAMP in the signal transduction of stress induced by heat shock and other environmental factors.

It has been shown that the plant cytokinin, 2iP, interacts with CAMP metabolism in both mammalian cells (Hecht et al., 1974) and prokaryotes (Coppola et al., 1976). Therefore, the discovery that $2 \mathrm{iP}$, at low concentrations $(0.25 \mathrm{mM})$, induces the same degree of thermotolerance as sublethal heat stress appeared to confirm the view of Shin et al. (1987) that cAMP-mediated phosphorylation may regulate the stress response in $S$. cerevisiae. Measurement of cAMP levels after addition of glucose revealed a large transient peak which has been reported to initiate cAMP-dependent phosphorylation (Thevelein, 1984b). However, after incubation with 2iP, ethanol or sublethal heat no significant increase in cAMP levels could be detected. Therefore, it appears $2 \mathrm{iP}$, ethanol and sublethal heat are able to induce thermotolerance by a mechanism independent of cAMP levels.

However, thermotolerance induced by sublethal heat is greatly reduced, and as induced by $2 \mathrm{iP}$ or ethanol is totally abolished, in strains without two of the three catalytic subunits of CAPK. This suggests that although 2iP, sublethal heat and ethanol do not increase cAMP (and thus cAMP-dependent phosphorylation), they do require the catalytic subunits of CAPK to induce full thermotolerance. This implies that these stress factors exert their effects independently of cAMP but directly on cAPK. This leads us to conclude that there may be a novel, stress-induced mechanism of activation of cAPK resulting in cAMP-independent protein phosphorylation by the kinase. Recently, Thevelein (1991) has reported a similar mechanism in nitrogen-starved cells. When they are provided with a nitrogen source there is no change in cAMP levels but they are able to activate, or deactivate, enzymes known to be regulated by cAMP-dependent protein phosphorylation.

Although it has been shown that cells need only one functional TPK gene to grow as well as wild-type cells (Toda et al., 1987b) there are indications that the 
presence or absence of different $T P K$ genes can lead to different phenotypes (Cameron et al., 1988). Our experiments support this by showing that strains with either TPK1 and TPK3 absent, or TPK1 and TPK2 absent have a reduced capacity for sublethal heat to induce thermotolerance, and have completely lost the capacity for $2 \mathrm{iP}$ and ethanol to induce thermotolerance.

Further evidence of the mode of action of $2 \mathrm{iP}$ comes from protein synthesis inhibition. Pre-treatment with cycloheximide totally abolishes the thermotoleranceinducing effect of $2 \mathrm{iP}$, and indeed, further sensitizes the cell to heat damage. There is evidence to suggest $2 \mathrm{iP}$ can stimulate protein synthesis in rat-derived $\mathrm{L}_{6}$ myoblasts (Yagasaki et al., 1986). So, it appears that the ability of $2 \mathrm{iP}$ to induce thermotolerance depends on de novo protein synthesis that involves phosphorylation via cAMP-independent activation of the kinase.

Intracellular trehalose synthesized during sublethal heat stress (Hottiger et al., 1987a; Attfield, 1987) has been proposed to be part of the protective mechanism of thermotolerance. Because trehalose metabolism and induced thermotolerance are believed to be regulated by protein phosphorylation we investigated the synthesis of trehalose induced by stress factors in strains with deletions in two of the three $T P K$ genes. The large increase in trehalose observed after sublethal-heatinduced thermotolerance does not occur when $2 \mathrm{iP}$ and ethanol induce thermotolerance. If there is a common mechanism of thermotolerance, this would suggest that the synthesis of trehalose is merely coincidental during sublethal heating. However, this seems unlikely as we have shown that strains with disrupted TPK genes have reduced thermotolerance with sublethal heat and a correlating reduction in trehalose levels. This would still mean that $2 \mathrm{iP}$ and ethanol induce thermotolerance by a mechanism other than trehalose synthesis. Further work with mutant strains unable to synthesize trehalose may help to resolve this question.

It is believed that trehalose increases as a result of dephosphorylation of trehalase and trehalose-6-phosphate synthase (Thevelein, 1984; Hottiger et al., 1987b). The activation of trehalase by sublethal heat has now been shown to be an artefact (De Virgilio, 1991) but trehalose-6-phosphate synthase activity increases about 6-fold during sublethal heating (Hottiger et al., 1987b). This may be due to dephosphorylation or, if the enzyme is a HSP, increased synthesis of the enzyme. Incubation with cycloheximide reduced the amount of trehalose synthesized, suggesting that the increase in trehalose is at least partially due to synthesis of trehalose-6-phosphate synthase. However, the reduction in trehalose synthesized during sublethal heat stress in the TPK mutant strains suggest certain cAPK catalytic subunits also play a role in activating the enzyme or, perhaps deactivating trehalase. Previous results (Hottiger et al., 1987a; Attfield, 1987) have shown correlations between levels of trehalose and degree of thermotolerance but there is still no definitive proof that trehalose is a 'stress-protectant'.

In summary, we believe that sublethal heat induces thermotolerance by a novel mechanism independent of cAMP levels but part-mediated by the catalytic subunits of cAPK. In contrast, $2 \mathrm{iP}$ and ethanol also induce thermotolerance by a mechanism independent of cAMP levels but fully dependent on the catalytic subunits of cAPK. In the case of $2 \mathrm{iP}$, it also appears to be dependent on protein synthesis. Both $2 \mathrm{iP}$ and ethanol did not increase trehalose levels suggesting that either trehalose synthesis is coincidental with heat stress, or there are different mechanisms of thermotolerance induced by different stresses. However, there was good correlation between levels of trehalose synthesized and the degree of thermotolerance induced by sublethal heat. Disruption of $T P K$ genes reduced sublethal-heat-induced trehalose synthesis, suggesting the importance of the catalytic subunits of cAPK in trehalose metabolism. The use of protein synthesis inhibitors indicated the possibility that trehalose-6-phosphate synthase could be synthesized during heat stress and thus account for increased trehalose.

The complexity of the cellular response to stress is now becoming apparent. It has been suggested that there are HSP-independent and -dependent mechanisms of thermotolerance (Coote et al., 1991 $a$ ) and the data presented here suggest that there may be a cAMP-independent mechanism. Further studies will use strains with mutations in $B C Y I$ (encoding the protein kinase regulatory subunit) as well as in TPK, to examine the cAMPindependent mechanism of thermotolerance in more detail. The role of $\mathrm{pH}_{\mathrm{i}}$ in regulating some enzymes critical to the cellular response to stress, e.g. adenyl cyclase (Valle et al., 1986), and the stress response itself (Panaretou \& Piper, 1990; Coote et al., 1991a) is now known. Perhaps the cell uses a single environmentally sensitive signalling factor, e.g. $\mathrm{pH}_{\mathrm{i}}$, to initiate the stress response. The mechanism of thermotolerance subsequently induced, rather than being a single unifying mechanism, could be due to a contribution from several factors, e.g. HSPs, ATPase and trehalose.

Finally, only by linking the range of physiological responses to stress can an overall understanding of this multi-component mechanism of thermotolerance be achieved.

The authors would like to thank Dr P. Piper for providing strains and stimulating discussions. We are also indebted to Professor $\mathbf{J}$. M. Thevelein and $W$. Verheyden for invaluable assistance in measuring cAMP, and Dr G. S. A. B. Stewart for constructive criticism. 


\section{References}

ATTFIELD, P. V. (1986). Trehalose accumulates in Saccharomyces cerevisiae during exposure to agents that induce heat shock response. FEBS Letters 225, 259-263.

BeEbe, S. J. \& Corbin, J. D. (1986). Cyclic nucleotide-dependent protein kinases. In The Enzymes, vol. 17, pp. 43-111. Edited by P. D. Boyer. New York: Academic Press.

Cameron, S., Levin, L., Zoller, M. \& Wigler, M. (1988). cAMPindependent control of sporulation, glycogen metabolism, and heat shock resistance in $S$. cerevisiae. Cell 53, 555-566.

Camonis, J. H., Kalekine, M., Gondre, B., Garreau, H., BoyMARCOTTE, E. \& JACQUET, M. (1986). Characterization, cloning and sequence analysis of the $C D C 25$ gene which controls the cyclic AMP level of Saccharomyces cerevisiae. EMBO Journal 5, 375-380.

CANNON, J. F. \& TATCHELL, K. (1987). Characterisation of Saccharomyces cerevisiae genes encoding subunits of cyclic AMP-dependent protein kinase. Molecular and Cellular Biology 7, 2653-2663.

COOTE, P. J., Cole, M. B. \& JoNes, M. V. (1991a). Induction of increased thermotolerance in Saccharomyces cerevisiae may be triggered by a mechanism involving intracellular $\mathrm{pH}$. Journal of General Microbiology 137, 1701-1708.

Coote, P. J., Cole, M. B. \& Holyoak, C. (1991b). Thermal inactivation of Listeria monocytogenes during a process simulating temperatures achieved during microwave heating. Journal of Applied Bacteriology 70, 489-494.

Coppola, S., ZoINA, A. \& MARINo, P. (1976). Interactions of $N^{6}-\left(\Delta^{2}-\right.$ isopentenyl)adenine with cyclic AMP on the regulation of growth and $\beta$-galactosidase synthesis in Escherichia coli. Journal of General Microbiology 94, 436-438.

Crowe, J. H., Crowe, L. M., Carpenter, J. F. \& Wistrom, C. A. (1987). Stabilisation of dry phospholipid bilayers and proteins by sugars. Biochemical Journal 242, 1-10.

De Virgilio, C., Burckert, N., Boller, T. \& Wiemken, A. (1991). A method to study the rapid phosphorylation-related modulation of neutral trehalase activity by temperature shifts in yeast. FEBS Letters 291, 355-358.

HeCht, S. M., Faulkner, R. D. \& Hawrelak, S. D. (1974). Competitive inhibition of beef heart cyclic AMP phosphodiesterase by cytokinins and related compounds. Proceedings of the National Academy of Sciences of the United States of America 71, 4670-4674.

HotTIGER, T., BOLLER, T. \& WiEMKEN, A. (1987a). Rapid changes of heat and desiccation tolerance correlated with changes of trehalose content in Saccharomyces cerevisiae cells subjected to temperature shifts. FEBS Letters 220, 113-115.

HotTIGER, T., SCHMUTZ, P. \& WiEMKen, A. (1987 b). Heat-induced accumulation and futile cycling of trehalose in Saccharomyces cerevisiae. Journal of Bacteriology 169, 5518-5522.

HotTIGER, T., Boller, T. \& WiEMKEN, A. (1989). Correlation of trehalose content and heat resistance in yeast mutants altered in the RAS/adenylate cyclase pathway: is trehalose a thermoprotectant? FEBS Letters 255, 431-434.

Krebs, E. G. \& BeAvo, J. A. (1979). Phosphorylation-dephosphorylation of enzymes. Annual Review of Biochemistry 48, 923-959.

Lillie, S. H. \& Pringle, J. R. (1980). Reserve carbohydrate metabolism in Saccharomyces cerevisiae: responses to nutrient limitation. Journal of Bacteriology 143, 1384-1394.

Matsumoto, K., UNo, I., Oshima, Y. \& Ishikawa, T. (1982). Isolation and characterization of yeast mutants deficient in adenylate cyclase and CAMP-dependent protein kinase. Proceedings of the National Academy of Sciences of the United States of America 79, 2355-2359.

Matsumoto, K., Uno, I. \& Ishikawa, T. (1983). Control of cell division in Saccharomyces cerevisiae mutants defective in adenylate cyclase and cAMP-dependent protein kinase. Experimental Cell Research 146, 151-161.

Mazon, M. J., Gancedo, J. M. \& Gancedo, C. (1982). Phosphorylation and inactivation of yeast fructose-1,6-biphosphatase in vivo by glucose and by proton ionophores. A possible role for cAMP. European Journal of Biochemistry 127, 605-608.

Panaretou, B. \& PiPeR, P. W. (1990). Plasma-membrane ATPase action affects several stress tolerances of Saccharomyces cerevisiae and Schizosaccharomyces pombe as well as the extent and duration of the heat shock response. Journal of General Microbiology 136, 17631770.

Panek, A. C., De Araujo, P. S., Neto, V. M. \& Panek, A. D. (1987). Regulation of the trehalose-6-phosphate synthase complex in Saccharomyces. Current Genetics 11, 459-465.

PIPER, P. (1990). Interdependence of several heat shock gene activations, cyclic AMP decline and changes at the plasma membrane of Saccharomyces cerevisiae. Antonie van Leeuwenhoek 58 , 195-201.

Plesset, J., Ludwig, J. R., Cox, B. S. \& Mclaughlin, C. S. (1987). Effect of cell cycle position on thermotolerance in Saccharomyces cerevisiae. Journal of Bacteriology 169, 779-784.

Praekelt, U. M. \& Meacock, P. A. (1990). HSP12, a new heat shock gene of Saccharomyces cerevisiae: analysis of structure, regulation and function. Molecular and General Genetics 223, 97-106.

SANCHEZ, Y. \& LINDQUisT, S. L. (1990). HSP104 required for induced thermotolerance. Science 248, 1112-1115.

Shin, D., Matsumoto, K., IIDA, H., UNo, I. \& Ishikawa, T. (1987). Heat shock response of Saccharomyces cerevisiae mutants altered in cyclic AMP-dependent protein phosphorylation. Molecular and Cellular Biology 7, 244-250.

Thevelein, J. M. (1984a). Activation of trehalase by heat shock in yeast ascospores: correlation with total cellular cyclic-AMP content. Current Microbiology 10, 159-164.

Thevelein, J. M. (1984b). Regulation of trehalose mobilization in fungi. Microbiological Reviews 48, 42-59.

Thevelein, J. M. (1988). Regulation of trehalase activity by phosphorylation-dephosphorylation during developmental transitions in fungi. Experimental Mycology 12, 1-12.

TheVelein, J. M. (1991). Fermentable sugars and intracellular acidification as specific activators of the RAS-adenylate cyclase signalling pathway in yeast: the relationship to nutrient-induced cell cycle control. Molecular Microbiology 5, 1301-1307.

Thevelein, J. M. \& Beullens, M. (1985). Cyclic AMP and the stimulation of trehalase activity in the yeast Saccharomyces cerevisiae by carbon sources, nitrogen sources and inhibitors of protein synthesis. Journal of General Microbiology 131, 3199-3209.

Thevelein, J. M., Beullens, M., Honshoven, F., Hoebeeck, G., Detremerie, K., Den Hollander, J. A. \& Jans, W. W. H. (1987) Regulation of the cAMP level in the yeast Saccharomyces cerevisiae: intracellular $\mathrm{pH}$ and the effect of membrane depolarizing compounds. Journal of General Microbiology 133, 2191-2196.

Toda, T., Cameron, S., Sass, P., Zoller, M., Scott, J. D., MCMullen, B., Hurwitz, M., KRebs, E. G. \& Wigler, M. (1987a). Cloning and characterization of $B C Y l$, a locus encoding a regulatory subunit of the cyclic AMP-dependent protein kinase in Saccharomyces cerevisiae. Molecular and Cellular Biology 7, 13711377.

Toda, T., Cameron, S., Sass, P., Zoller, M. \& Wigler, M. (1987b). Three different genes in $S$. cerevisiae encode the catalytic subunits of the cAMP-dependent protein kinase. Cell 50, 277-287.

Valle, E., Bergillos, L., Gascon, S., Parra, F. \& Ramos, S. (1986). Trehalase activation in yeasts is mediated by an internal acidification. European Journal of Biochemistry 154, 247-251.

Van Der Plaat, J. B. (1974). Cyclic 3',5'-adenosine monophosphate stimulates trehalose degradation in baker's yeast. Biochemical and Biophysical Research Communications 56, 580-587.

Watson, K., Dunlop, G. \& Cavicchioli, R. (1984). Mitochondrial and cytoplasmic protein synthesis are not required for heat shock acquisition of ethanol and thermotolerance in yeast. FEBS Letters 172, 299-302.

WIEMKEN, A. (1990). Trehalose in yeast, stress protectant rather than reserve carbohydrate. Antonie van Leeuwenhoek 58, 209-217.

WiemKen, A. \& SChellenberG, M. (1982). Does a cyclic-AMP dependent phosphorylation initiate the transfer of trehalase from the cytosol into the vacuoles in Saccharomyces cerevisiae? FEBS Letters 150, 329-331.

YAGASAKI, K., Shinonaga, M. \& Funabiki, R. (1986). Effect of isopentenyladenine, a cytokinin, on proliferation and protein synthesis in cultured myoblasts. Agricultural and Biological Chemistry 50, 2791-2794. 